\title{
Kabuki Syndrome: Case Study Report
}

\author{
Giovanna Franco Tini ${ }^{1 *}$, Amanda Caramel Juvino ${ }^{1}$, Markus Algayer Atmanspacher ${ }^{1}$, Carolina \\ Algayer Atmanspacher ${ }^{1}$, Caroline Berne Pereira ${ }^{1}$, Rodolfo Georgevich Neto ${ }^{1}$, Marina Struncova \\ Fernandes $^{1}$, Ruth Andia-Merlin ${ }^{2}$, Gilberto Araújo Noro Filho ${ }^{2}$ and Elcio Magdalena Giovani ${ }^{3}$ \\ ${ }^{1}$ Students of the Faculty of Dentistry of UniversidadePaulista, FOUNIP, Sao Paulo, Brazil \\ ${ }^{2}$ Master and PhD student in Oral Diagnosis, Professor of the Discipline of Integrated Clinic and Patients with Special Needs - CEAPE (School of \\ Dentistry of UniversidadePaulista), FOUNIP, Sao Paulo, Brazil \\ ${ }^{3}$ Master in Oral Pathology, Ph.D. in Integrated Clinic, Full Professor of Integrated Clinical Discipline and Patients with Special Needs, Professor of \\ Master's and Ph.D. Program, Coordinator of CEAPE, Dentistry Course of the Faculty of Dentistry of UniversidadePaulista, FOUNIP, Sao Paulo, Brazil
}

Received: December, 12, 2016; Accepted: February, 24, 2017; Published: March 03, 2017

*Corresponding author: Giovanna Franco Tini, Students of the Faculty of Dentistry of universidadepaulista, FOUNIP, Sao Paulo, Brazil, Tel:(+55)1195885-6410;E-mail:giovanna.franco.tini@hotmail.com

\begin{abstract}
Kabuki syndrome is a rare congenital anomaly, in which such (optional) patients present mild to moderate mental deficits and are characterized by unusual facial expressions. In addition, they may also manifest cardiac anomalies, urinary tract anomaly, hearing loss, hypotonia and also postnatal growth deficit. These fundamental characteristics are called "Pentad of Niikawa", which correspond to dysmorphic face, skeletal anomalies, dermatoglyphic abnormalities, mild to moderate mental deficit, and postnatal growth deficiency. It also includes scoliosis, malformation of spinal column and ribs, delay in skeletal maturation, dislocation of the hip and patellar. The aim of this case study report is to present the diagnosis of a patient with this syndrome, evidencing, in the light of knowledge, to the Dental Surgeons of how to conduct dental treatment with effectiveness and safety. It also shows the need for an interdisciplinary and multidisciplinary approach for the treatment of these patients, highlighting all of the complexity of the syndrome, making it easier future diagnoses, with a purpose of promoting integral health and improvements in the quality of life.
\end{abstract}

Keywords: Kabuki syndrome; Special Patients; Dental treatment

\section{Introduction}

Kabuki Syndrome is a rare congenital anomaly, autosomal dominant that was firstly described in 1981. It presents this designation due to the peculiar facial features of its hosts, resembling those of Kabuki traditional Japanese theatre makeup $[1,2,3]$. Its frequency is estimated at 1:32.000 [4].

Niikawa etal (1981), Niikawa et al (1988), Gabrieli et al (2012) clarify the syndrome based on five fundamental characteristics: dysmorphic face, skeletal anomalies, dermatoglyphic abnormalities, mild to moderate mental deficit, and postnatal growth deficiency $[1,5,6,7]$.

Facial characteristics are lower eyelid eversion, long palpebral fissures, thick and bent eyebrows, saddle nose and depressed nasal tip, malformation of the ears, preauricular fissure, blue sclera, strabismus. The cleft palate, arched palate, abnormal teething, microdontia are some of the intra-oral alterations found in these patients [4].

Regarding the neurological alterations, one may present soft to mild mental retardation, seizures, microcephaly, hypotony. Skeletal anomalies (short fingers, scoliosis and hip luxation) as well as visual may also appear [4].

Systemically, cardiac anomalies might manifest (occurrence in $30 \%$ of the cases). Additionally, there might be some cases related to the urinary tract, hearing loss, increase of susceptibility to infections, autoimmune diseases, loose joints and hypermobility, hypotony and postnatal growth dawdling (occurrence in $83 \%$ of the cases) $[4,6,8]$.

A fair amount of the patients who happen to be hosts for the syndrome have shown an autistic behavior with stereotypical and repetitive movements [7].

The diagnosis is clinical at its core, based on facial alterations, growth abnormalities and postnatal growth deficit ${ }^{1}$. The genetic mapping can assist the preventive diagnosis $[10,11,12,13,14]$.

The aim of this paper resides on describing a clinical case of dental intervention in a patient who has been diagnosed with Kabuki Syndrome.

\section{Case Study Report}

Patient GDSC, 12 years old, Brazilian, female, leucoderma, diagnosed at the age of three as a Kabuki Syndrome host without previous family history. According to the mother, during the anamnesis, that "baby was long overdue" (sic), cesarean section birth, cyanotic delivery. In addition, it was declared that throughout the 11 months "she needed to place the rip in the right position" (sic) [4]. The patient present other systemic alterations associated with the syndromic scenario, myopia, asthma and pneumonia chart. After the diagnosis, medical follow-up was initiated and maintained with a neurologist, psychologist, speech therapist, geneticist, nutritionist and pneumologist. 
She sought the CEAPE FOUNIP, (Center for Studies and Assistance to Patients with Special Needs), portraying as main complaint the orthodontic treatment. The extra-oral exam has shown prominent frontal fossa (Figure 1), hypertelorism, bent eyebrows, eversion of the external portion of the lower eyelid (Figure 2) and ligament laxity (Figure 3). Intra-oral examination has displayed ogival palate, maxillary atresia at the anterior portion with dental crowding (Figure 4), macroglossia (Figure 5), repetitive bite in the jugal mucosa, agenesis of the lateral inferior incisor (Figure 6) and white active lesion spot in the vestibular of the 33 tooth, high rate of dental plaque (55\%), brushing the teeth
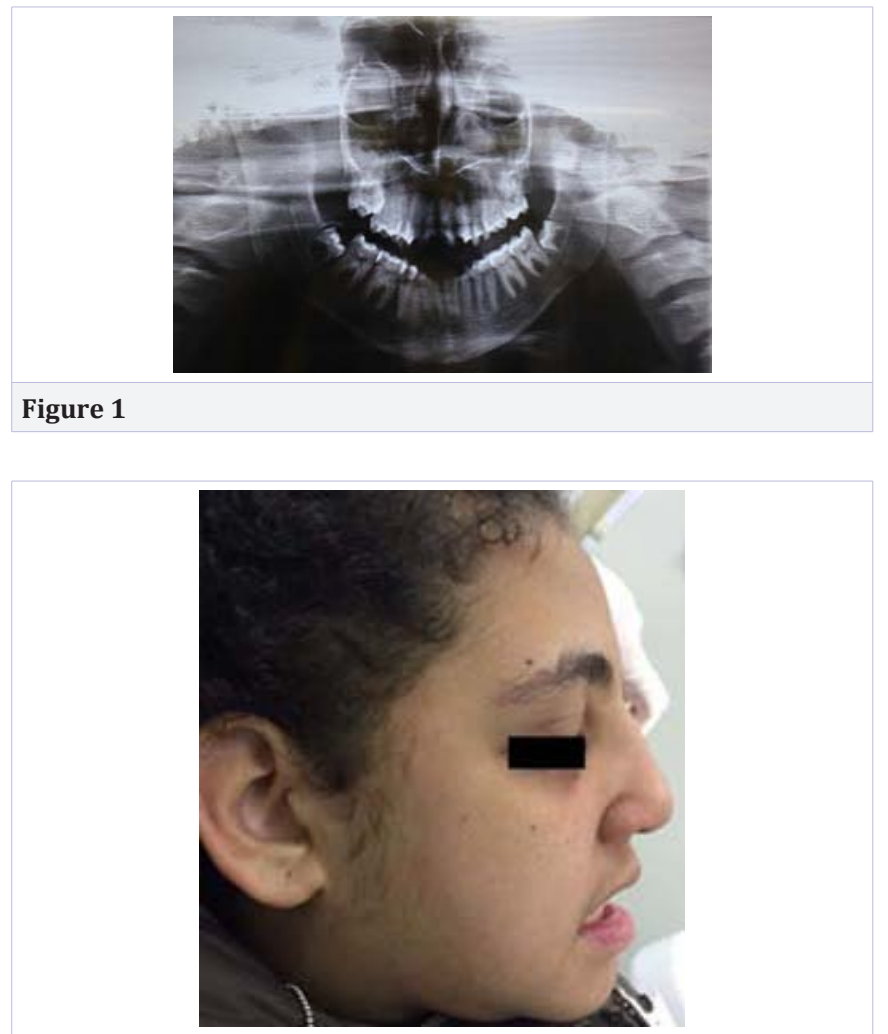

Figure 2

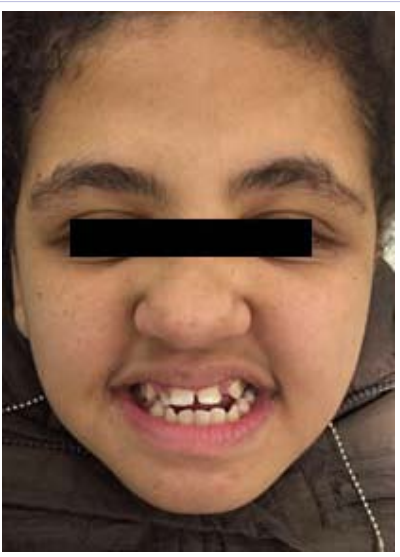

Figure 3

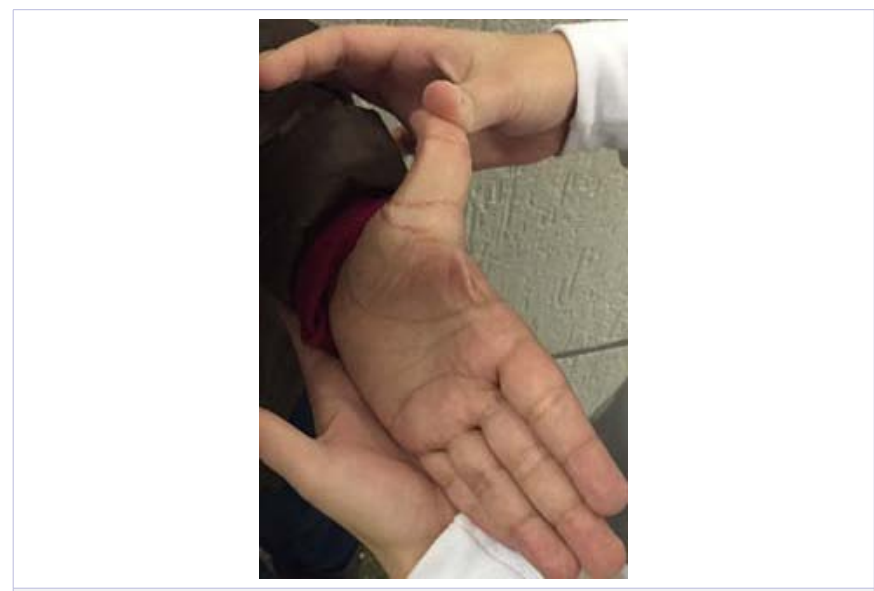

Figure 4

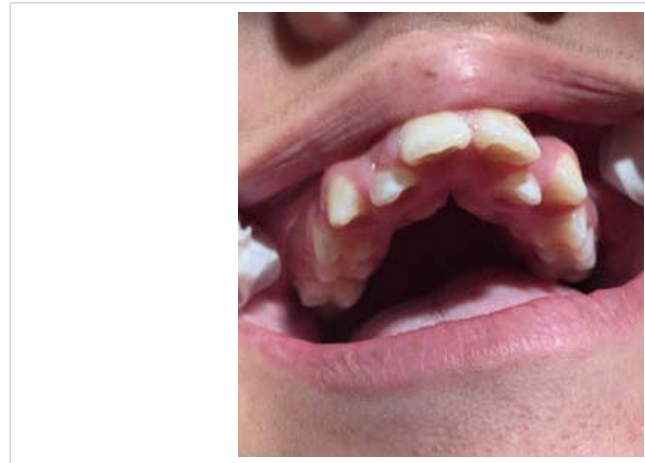

Figure 5

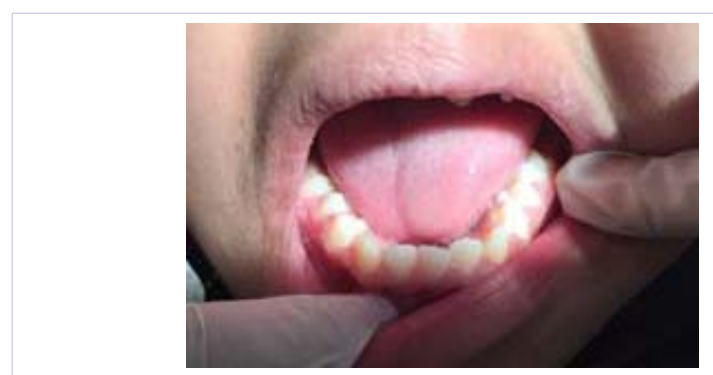

Figure 6

only once a day and no use of dental floss and a cariogenic highrisk diet. The initial treatment was the prevention with disclosing of the dental plaque, dental hygiene and diet orientation. Forwardly, fluoride varnish application has been made on the white active lesion spot and molars occlusal surface. Proservation was carried out during the year, performing appointments every 2 months and the patient was referred to orthodontic treatment.

\section{Conclusion}

The case study report demonstrates the need of interdisciplinary and multidisciplinary approach for the treatment of such patients with the goal of promoting integral health and enhancement in quality of life. Preventive intervention 
and bonding (patient, family/caretakers and dental surgeon) are essential factors that lead to the success of the recommended treatments. It is vital to remain focused on the existence of this syndrome and its complexity in order to facilitate assistance in future diagnosis.

\section{References}

1. Niikawa N, Matsuura N, Fukushima Y, Ohsawa T, Kajii T. Kabuki make-up syndrome: a syndrome of mentalretardation, unusual facies, large and protruding ears, and postnatal growth deficiency. J Pediatr. 1981;99(4):565-569.

2. María Soledad Andersen, Sebastián Menazzi, Paloma Brun, Cecilia Cocah, Giuseppe Merla, Andrea Solari. Diagnóstico clínico enel síndrome de Kabuki: fenótipo y anomalíasasociadasen dos casos nuevos. Arch.argent.pediatr. 2014;112(1):26-32. doi.org/10.5546/ aap.2014.e13

3. Medina, F. M. C. et al. Sindrome de Kabuki: relato de caso com alterações oculares severas. Revbrasoftalmol. 2013;72(5):341-343.

4. Fernandez PGE, Santana HEE, Rodriguez EA, Oro MY, Silva FSB. Presentacion de um paciente com sindrome Kabuki. Correo Cientifico medico de Holguin.2014;18(4):752-758.

5. Niikawa,N, Kuroki Y, Kajii T, Matsuura N, Ishikiriyama S, Tonoki H, et al. Kabuki make-up syndrome (Niikawa-Kuroki) syndrome: a study of 62 patients. Am J Med Genet. 1988;31(3):565-589. doi: 10.1002/ ajmg.1320310312

6. Ana Paula Tedesco Gabrieli , Fernanda Velho Rovaris, Laura Elaine Bisol , Lívia Borges, Marja Mandelli Michelin, Louise Lovatto. Sindrome da maquiagem de kabuki. Acta ortopbras. 2002;10(3):57-61.

7. Kawame H, Hannibal MC, Hudgins L, Pagon RA. Phenotypic spectrum and management issues in Kabuki syndrome. J Pediatr. 1999;134(4):480-485.

8. Bianca Mota dos Santos, Roberta Rezende Ribeiro,Adriana Sasso Stuani, Francisco Wanderley Garcia de Paula e Silva, Alexandra Mussolino de Queiroz. Kabuki Make-up (Niikawa-Kuroki) Syndrome:Dental and Craniofacial Findings in a Brazilian Child. Braz Dent J.2006;17(3):249254. doi.org/10.1590/S0103-64402006000300014

9. Suarez-Guerrero J L, Contreras-Garcia G A. Sindrome de Kabuki: caracterización clínica, estúdios genéticos, manejo preventivo de lascomplicaciones y asesoría genetica. Med.uis. 2012;25(1):19-27.

10. Miguel Lugones Botell, Marieta Ramírez Bermúdes, Luis Alberto Pichs Garcíay, Juan José Ríos Rodríguez. Sindrome de Kabuki. Rev Cubana Pediatr. 2006;78 (2).

11. Van Haelst, Alice S Brooks, Jeannette Hoogeboom, Marja W Wessels, Dick Tibboel, Johan C de Jongste, et al. Unexpected life-threatening complications in Kabukisyndrome.Am JMedGenet.200;94(2):170-173. doi: $\quad$ 10.1002/1096-8628(20000911)94:2<170::AIDAJMG10>3.0.CO;2-2

12. Banka S, Howard E, Bunstone S, Chandler KE, Kerr B, Lachlan K, et al. MLL2 mosaic mutations and intragenic deletion-duplications in patients with Kabuki syndrome. Clin Genet.2013;83(5):467-471. doi: 10.1111/j.1399-0004.2012.01955.x

13. Banka S, Veeramachaneni R, Reardon W, Howard E, Bunstone S, Ragge N, et al. How genetically heterogeneous is Kabuki syndrome? MLL2 testing in 116 patients, review, and analyses of mutation and phenotypic spectrum. Eur J Hum Genet. 2012;20(4):381-388. doi: 10.1038/ejhg.2011.220

14. Bögershausen N, Wollnik B. Unmasking Kabuki syndrome. Clin Genet. 2013;83(3):201-211. doi: 10.1111/cge.12051 